\title{
Fall as a cause of hospitalization in the Emergency Department in a population of people over 65 years of age
}

\author{
Grzegorz Józef Nowicki', Patryk Rzońca², Katarzyna Naylor³, Ewa Rudnicka-Drożak², \\ Magdalena Młynarska², Andrzej Prystupa ${ }^{4}$, Kamil Bednarz ${ }^{5}$ \\ ${ }^{1}$ Community Nursing Unit Chair of Oncology and Environmental Health, Medical University of Lublin, Poland \\ 2 Department of Expert Medical Assistance with Emergency Medicine Unit, Medical University of Lublin, Poland \\ ${ }^{3}$ Department of Didactics and Medical Simulation, Medical University of Lublin, Poland \\ ${ }^{4}$ Department of Internal Medicine, Medical University of Lublin, Poland \\ ${ }^{5}$ Voivodship Emergency Ambulance Service, Lublin, Poland
}

Nowicki GJ, Rzońca P, Naylor K, Rudnicka-Drożak E, Młynarska M, Prystupa A, Bednarz K. Fall as a cause of hospitalization in the Emergency Department in a population of people over 65 years of age. J Pre-Clin Clin Res. 2015; 9(2): 115-119. doi: 10.5604/18982395.1186490

\section{Abstract}

Introduction. Falls are included among the geriatric giants, as their consequences in older people are major in terms of nursing, medical, social and economic problems. In the case of elders they can lead to fractures and, consequently, even to death.

Materials and method. The study retrospectively analysed the medical records of 455 cases of injuries resulting from falls among patients over 65 years of age. Data was gathered in the Emergency Department (ER) of the Independent Public Clinical Hospital No. 1 in Lublin, Poland. The analysis included patients who visited the ER during the period 01.05.2009-30.04.2010.

Results. Elderly patients hospitalized in the ER within the given period accounted for $8.10 \%$ of all patients. Most of patients over 65 years of age were admitted in December due to falls; slightly fewer cases were recorded in March and April. Mondays and Saturdays were the days of the week with the highest number of reports of elderly patients. Analysis of the collected data incorporating further treatment showed that the great majority of injured patients did not require hospitalization and were discharged home. In the analyzed population of older people, damage to upper and lower limbs dominated, followed by injuries to the head, chest and abdomen.

Conclusion. Falls are a major cause of reduced quality of life, disability and death in older people. There are important factors in limb fractures (90\%-100\%). Preventing falls is a difficult and underestimated problem. There is a need of implementing preventative measures in the case of falls in elderly patients.

\section{Key words}

falls, elderly, epidemiology

\section{INTRODUCTION}

The aging of society is widespread and affects mainly developed countries. In Poland, there is a steady increase in number of people over 65 years of age. Census results show that on 31 March 2011 there were 38,511.8 citizens belonging to this category. In the period 2002-2011, the number of people at retirement age (60/65 or more) increased to $16.9 \%$ (i.e. 1.9 percentage points) of the total population. According to the population projection prepared by the Polish Central Statistical Office (GUS) in 2008, the years 2008-2035 are predicted to be a period of accelerating ageing of Polish population. The percentage of people aged $60+/ 65+$ in the structure of the population will increase from 16.8 to $26.7 \%[1,2]$.

The requirements of modern gerontology resulted in the introduction of a new concept called 'geriatric giants' [3]. These problems are most commonly connected with mental and physical disorders of a chronic nature, caused by many factors and difficult to treat [4]. They cause a gradual loss

Address for correspondence: Grzegorz Józef Nowicki, Community Nursing Unit Chair of Oncology and Environment Health Medical University, Lublin, Staszica, 20-153 Lublin, Poland

E-mail: grzesiek_nowicki@interia.pl

Received: 01 April 2015; accepted: 11 August 2015 of independence in older age. Unfortunately, despite its universality, they are ignored and treated by the environment as a 'natural' consequence of aging [3]. Geriatric giants include: falls and impaired mobility, urine and / or stool incontinence, impaired vision and / or hearing disorders, senile dementia and depression.

Research conducted in Germany show that $30 \%$ of the older patients hospitalized in rehabilitation clinics were there as a result of fractures resulting from falls $[4,5]$. The research carried out by Bosacka, Jozwiak and Wieczorkowska-Tobis on a group of 100 patients aged 62-93 years, showed that every third person suffered from a fall before going to the Department of Daily Psychogeriatric [5]. Epidemiological data show that among people 65 years of age and above, $35 \%$ experienced a fall in their own homes at least once a year. In the group over 80 years of age, the problem increases to $40 \%$, whereas after 90 years of age - up to $50 \%$. It is believed, however, that most often a fall is a characteristic of residents of nursing homes and social care homes, etc. [6]. Falls in $20 \%$ cases result in a serious injury [7]. The most common causes of falls are:

- diseases increasing the probability of fall (e.g. Parkinson's disease, depression, stroke);

- disease resulting in the loss of consciousness (e.g. neurocardiological fainting, arrhyth); 
- environmental factors;

- use of certain medications (e.g. psychotropic) [8].

It has been proven that the causes of falls in the elderly are the result of so-called external factors $[8,9]$. Each fall additionally triggers mental changes. Afterwards, there appears the so-called 'injury syndrome' or 'after fall syndrome' $[10,11,12]$. The physical consequences concern mainly fractures (requiring surgery or not), wounds and bruises [12].

\section{OBJECTIVE}

The aim of the study is to present some epidemiological data of patients over 65 years of age admitted in the Emergency Department because of a fall, and the analysis of further proceedings, as well as the location of injury depending on the variables: age, gender and place of residence. The epidemiological data can be used to estimate the cost of hospitalization and preparation of a base to for patients over 65 years of age.

\section{MATERIALS AND METHOD}

The study retrospectively analyzed 455 cases of injuries to different parts of body caused by falls among patients over 65 years of age in data of the Emergency Department (ED) of the Independent Public Clinical Hospital No. 1 (SPSK1) in Lublin. The analysis included patients admitted in the period from 1 May 2009-30 April 2010, carried out under the provisions of the Act on the Protection of Personal Data. In the given period, there were reported a total of 5618 people due to trauma, including those over 65 who accounted for $8.10 \%$ of cases.

The collected material contained information regarding proceedings with the patient and the type of injury according to International Statistical Classification of Diseases and Related Health Problems ICD-10. The analysis also took into account demographic information, such as gender, age and place of residence of the patients. In the analyzed documentation the following deficiencies were noted: time of admission -8 cases (1.76\%), and follow-up with the patient - 2 cases $(0.44 \%)$. Database and statistical calculations were based on computer software STATISTICA 10 (StatSoft Polska). The collected data were statistically analyzed and the relationships between variables was verified with $\chi^{2}$ test of independence attributes, taking the level of statistical significance of $\mathrm{p}<0.05$.

Characteristics of the study group. Among the 455 patients over 65 years of age admitted to the ER in the given period due to injuries caused by falls, women dominated, as they accounted for $68.57 \%(n=312)$ of cases. Men constituted $31.43 \%(\mathrm{n}=143)$ of cases. Most of the respondents were residents of the city $-84.84 \%(n=386)$ of cases, while residents of rural areas made up only $15.16 \%(n=69)$ of all those surveyed.

Older age is differently categorized according to various sources. The World Health Organization (WHO) experts consider that old age begins at the age of 65 [13], while the United Nations (UN) as a contractual beginning consider the age of 60 [14]. For the purposes of the presented research, the division proposed by the WHO was applied [15]. The following division of the elderly was employed, taking into account the age groups: 65-75 years - elderly age, 75-90 years - old age, 90 years and over - longevity. In the analyzed data, the patients aged 75-90 constituted the largest group $(54.07 \% ; \mathrm{n}=246)$. The second most numerous group were patients aged $65-74(39.56 \%, \mathrm{n}=180)$. Patients aged 90 and more represented the smallest age group among respondents $(96.37 \%, \mathrm{n}=29)$.

\section{RESULTS}

The largest number of admissions to the Emergency Department caused by falls among the elderly was noted in December $(10.55 \%, \mathrm{n}=48)$, while slightly fewer cases were reported in March $(9.45 \%, \mathrm{n}=43)$ and April $(9.45 \%, \mathrm{n}=43)$. The smallest number of admissions occurred in September (6.81\%, $\mathrm{n}=31)$ and August (7.03\%, n=32) (Fig.1). Mondays $(18.02 \%, \mathrm{n}=82)$ and Saturdays $(16.70 \%, \mathrm{n}=76)$ were the days of the week with the highest number of surveyed, and accounted for almost $25 \%$ of all admissions. The least number of patients were admitted on Fridays (Fig. 2). The highest intensity of reports of patients with injury arising as a result of falls were admitted between 12:00-15:59, which was over $30 \%$ of all cases. (Tab. 1).

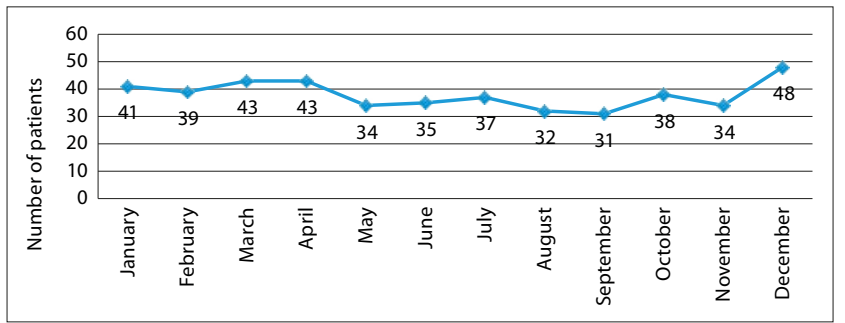

Figure 1. Number of patients over 65 years reporting injury as a result of falls in each month

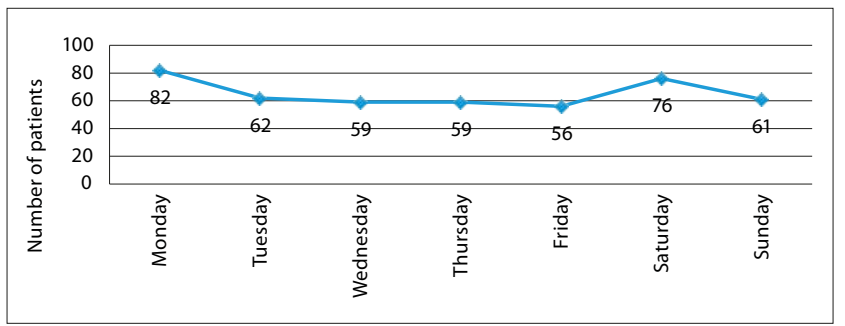

Figure 2. Number of patients over 65 years reporting injury as a result of falls in particuar days of the week.

Table 1. Number of admitted patients over 65 years of age according to particular hours

\begin{tabular}{lcc}
\hline Admission time & $\mathrm{N}$ & $\%$ \\
\hline $0: 00-3: 59$ & 8 & 1,76 \\
\hline $4: 00-7: 59$ & 9 & 1,98 \\
\hline $8: 00-11: 59$ & 116 & 25,49 \\
\hline $12: 00-15: 59$ & 153 & 33,63 \\
\hline $16: 00-19: 59$ & 113 & 24,84 \\
\hline $20: 00-23: 59$ & 48 & 10,55 \\
\hline B/D & 8 & 1,76 \\
\hline
\end{tabular}


Falls among patients over 65 years old and studied variables. Analysis of the collected data showed that the great majority of patients who lived in both the urban the area $(75.52 \% ; n=290)$ and rural areas $(63.77 \% ; n=44)$, after their injuries had been tended to, did not require hospitalization and were discharged home. Patients living in rural areas $(28.99 \% ; n=20)$ more often than those living in urban areas (19.79\%; $\mathrm{n}=76)$ required further treatment at the Department of Traumatology and Emergency Medicine. Additionally, women $(75.16 \% ; n=233)$ were slightly more likely than men (70.63\%; $\mathrm{n}=101)$ to leave the ER after initial treatment of a personal injury However, the collected data showed that women $(21.29 \% ; n=66)$ more frequent than men $(20.98 \%$; $\mathrm{n}=30$ ) required more advanced treatment and hospitalization at the Department of Trauma and Emergency Medicine. The elderly aged $65-75$ years $(80.56 \%, \mathrm{n}=145)$ more frequently than patients aged $75-90(69.26 \% ; n=169)$ and aged 90 or more $(68.97 \% ; n=20)$ could be discharged home after an initial treatment. In contrast, a higher percentage of patients aged $75-89$ years $(25.82 \%, n=63)$ required treatment for an injury at the trauma unit, similar to patients aged 90 years and older $(24.14 \% ; \mathrm{n}=7)$. Patients aged $65-74$ years $(14.44 \%$; $\mathrm{n}=26$ ) most rarely required further care regarding their injury. No statistically significant relationship was observed between proceeding with the patient and analyzed variables p> 0.05 (Tab. 2).

When taking into account the location of injury and place of residence of patients, the analyzed data indicated that patients living both in urban area and rural areas most often experienced injuries of the upper limbs and lower limbs. Patients living in an urban area more frequently than patients living in a rural area experienced a head injury (town: $25.65 \% ; \mathrm{n}=99$; village: $20.29 \% ; \mathrm{n}=14$ ) and abdomenal injury (uraban: $4.66 \% ; n=18$; rural $2.90 \% ; n=2$ ), while those living in rural areas more often experienced upper extremity injuries (Urban: 33.33\%; $\mathrm{n}=23$; rural: $31.87 \%$; $=123$ ), lower limbs (urban: $33.33 \%$; $\mathrm{n}=23$; rural: $27.98 \% ; \mathrm{n}=108$ ) and chest (urban: $8.70 \% ; \mathrm{n}=6$; irural: $7.25 \%$; $\mathrm{n}=28$ ). Women were more likely than men to experience upper extremity injuries (females: $34.29 \% ; \mathrm{n}=107$; males: $27.27 \%$; $\mathrm{n}=39$ ) and lower limbs injuries (females: 29.17\%; $\mathrm{n}=91$; males: 27 , $97 \% ; \mathrm{n}=40$ ), while men more often than women experience head injuries (females: $23.72 \% ; \mathrm{n}=74$; males: $27.27 \%$; $\mathrm{n}=$ 39). Patients aged $65-74$ years $(35.56 \% ; n=64)$ most often experienced injuries of the upper limbs, and patients aged $75-89$ years less frequently $(31.30 \% ; \mathrm{n}=77)$. On the other hand, patients aged 90 and older $(17.24 \% ; n=5)$ most rarely experienced upper extremity injuries. Among patients aged 90 or more years, the most common bodily injury turned out to be head injuries $(44.83 \% ; n=13)$. Patients aged $65-75$ years and 75-90 years suffered most commonly from injuries of the upper limbs ( $65-75$ years: $35.56 \% ; \mathrm{n}=64 ; 75-89$ years: $31.30 \% ; \mathrm{n}=77)$ and damage to the lower limbs (65-75 years: $27.78 \% ; n=50 ; 75-89$ years: $29.27 \% ; n=72$ ). There was no significant statistical relationship between the injury and its location and the place of residence, gender and respondents aged 65 (Tab. 3).

\section{DISCUSSION}

The American Geriatric Society and British Geriatric Society define a fall as 'an event during which a person assumes a lying position on the level at which he/she was standing, or lower level, with or without loss of consciousness' [16]. On the other hand, according to the WHO definition, a fall is 'an event by which a person accidentally finds himself/ herself on the ground, floor, or other lower level.' According to this definition, the WHO statistics do not include selfinflicted injuries, falls from animals, from burning buildings,

Table 2. Relationship between further treatment of the patient and variables analysed

\begin{tabular}{|c|c|c|c|c|c|c|c|c|c|c|c|c|c|c|}
\hline \multirow[t]{3}{*}{ Further treatment } & \multicolumn{4}{|c|}{ Place of residence } & \multicolumn{4}{|c|}{ Gender } & \multicolumn{6}{|c|}{ Age } \\
\hline & \multicolumn{2}{|c|}{ City } & \multicolumn{2}{|c|}{ Country } & \multicolumn{2}{|c|}{ Female } & \multicolumn{2}{|c|}{ Male } & \multicolumn{2}{|c|}{$65-74$ years } & \multicolumn{2}{|c|}{ 75-89years } & \multicolumn{2}{|c|}{90 and more } \\
\hline & $\mathrm{N}$ & $\%$ & $\mathrm{~N}$ & $\%$ & $\mathrm{~N}$ & $\%$ & $\mathrm{~N}$ & $\%$ & $\mathrm{~N}$ & $\%$ & $\mathrm{~N}$ & $\%$ & $\mathrm{~N}$ & $\%$ \\
\hline Discharge & 290 & 75.52 & 44 & 63.77 & 233 & 75.16 & 101 & 70.63 & 145 & 80.56 & 169 & 69.26 & 20 & 68.97 \\
\hline Traumatology & 76 & 19.79 & 20 & 28.99 & 66 & 21.29 & 30 & 20.98 & 26 & 14.44 & 63 & 25.82 & 7 & 24.14 \\
\hline Others & 18 & 4.69 & 5 & 7.25 & 11 & 3.55 & 12 & 8.39 & 9 & 5.00 & 12 & 4.92 & 2 & 6.90 \\
\hline
\end{tabular}

Table 3. Relationships between the location of injury and variables analyzed

\begin{tabular}{|c|c|c|c|c|c|c|c|c|c|c|c|c|c|c|}
\hline \multirow[t]{3}{*}{ Injuries according to ICD - 10} & \multicolumn{4}{|c|}{ Place of residence } & \multicolumn{4}{|c|}{ Gender } & \multicolumn{6}{|c|}{ Age } \\
\hline & \multicolumn{2}{|c|}{ City } & \multicolumn{2}{|c|}{ Country } & \multicolumn{2}{|c|}{ Female } & \multicolumn{2}{|c|}{ Male } & \multicolumn{2}{|c|}{$65-74$ years } & \multicolumn{2}{|c|}{$75-89$ years } & \multicolumn{2}{|c|}{90 and more } \\
\hline & $\mathrm{N}$ & $\%$ & $\mathrm{~N}$ & $\%$ & $\mathrm{~N}$ & $\%$ & $\mathrm{~N}$ & $\%$ & $\mathrm{~N}$ & $\%$ & $\mathrm{~N}$ & $\%$ & $\mathrm{~N}$ & $\%$ \\
\hline Head trauma & 99 & 25.65 & 14 & 20.29 & 74 & 23.72 & 39 & 27.27 & 41 & 22.78 & 59 & 23.98 & 13 & 44.83 \\
\hline Chest trauma & 28 & 7.25 & 6 & 8.70 & 23 & 7.37 & 11 & 7.69 & 12 & 6.67 & 21 & 8.54 & 1 & 3.45 \\
\hline Abdominal injuries & 18 & 4.66 & 2 & 2.90 & 13 & 4.17 & 7 & 4.90 & 7 & 3.89 & 12 & 4.88 & 1 & 3.45 \\
\hline Lower limbs injuries & 108 & 27.98 & 23 & 33.33 & 91 & 29.17 & 40 & 27.97 & 50 & 27.78 & 72 & 29.27 & 9 & 31.03 \\
\hline Others & 10 & 2.59 & 1 & 1.45 & 4 & 1.28 & 7 & 4.90 & 6 & 3.33 & 7 & 2.03 & 0 & 0.00 \\
\hline Total & 386 & 100.00 & 69 & 100.00 & 312 & 100.00 & 143 & 100.00 & 180 & 100.00 & 246 & 100.00 & 29 & 100.00 \\
\hline
\end{tabular}


transport vehicles and machines, as well as falls into the water [17]. In the case of older people, falls and their consequences are one of the most common and solemn health problems. The fall itself can also be the first symptom of the coexistence of other illnesses $[16,17]$. Falls account for $100 \%$ of fractures of the forearm, $90 \%$ of fractures of the proximal femur and $25 \%$ of vertebral fractures. Even more, they lead to a reduction in mobility, decreased physical activity, increased, and are often the cause of death. Furthermore, the elderly who have fallen once, twice or three times a year, are more likely to re-experience a fall [16]. Additionally, they constitute a group of people covered early by long-term medical care $[16,17]$.

Analysed data showed that the highest number of falls among older people was recorded in December (10.55\%), whereas the lowest were noted in September and August $(6.81 \%$ and $7.03 \%$ ). The obtained results confirm the widespread belief that winter accounts for a higher injury rate among older people. On the other hand, research by Czerwinski et al. [18] in which 50 randomly selected patients of the Cracow Medical Centre were surveyed, found that between 2001 and 2006, among patients over 50 years of age (mean age 65 years), falls prevailed in the summer months (37.7\%), followed by winter (19.5\%) and spring (18.2\%)

Monday and Saturday accounted for nearly $25 \%$ of all admissions to the ER, while the lowest number of patients was noted on Fridays. Moreover, most falls occurred during the day, between 12:00-15:59 (over 30\%). The obtained results correspond with the results of Czerwiński et al. [18]. Similar data were obtained from a retrospective analysis by Grochans et al. of the medical records of 152 patients in a geriatric ward of the Malteser Krankenhaus in Berlin [19]. The study noted that most often the falls occurred in the case of geriatric patients in the early afternoon (12:00-14:00) and in the early evening (16:00-20:00), whereas the lowest rate of falls were noted between 14:00-16:00 and 22:00-0:00.

Advanced age is the confirmed risk factor for falls [12] and according to Zakowski-Wachelko, the risk of falling increases with age. The disabled and incapacitated elderly are particularly prone to falls, and - paradoxically - those who are healthy, busy, and highly mobile [20]. The results obtained in the presented study confirm the increase in the incidence regarding falls with age, with the age range 65-75 years characterized over 39\%, while those between 75-89 accounted for over $54 \%$ of the admitted seniors. A similar pattern was noted in research by Pin Tan et al. [21].

The research shows that the studied group was most commonly characterized by injuries affecting the upper and lower limbs, followed by injuries to the head, chest and abdomen. Retrospective analysis of the medical records of patients hospitalized in the Department of Trauma Surgery and Rescue Medicine between 2008-2009 carried out by Miturski et al. [22] proved that the most common fracture in the elderly were fractures of the proximal femur. In contrast, the results of Szczerbiński [23], conducted among 822 residents in seven Social Welfare Homes in Cracow, showed that most falls were related to head injuries (41.72\%), followed by the lower extremities (16.89\%), upper extremities (12.58\%) and trunk (11.26\%).

Progressive degenerative changes occurring with age, comorbidities, medications and history of injuries reduce the efficiency of the elderly, and consequently favour the occurrence of falls. These 'geriatric giants' refer to every third person over 65 years of age $[24,25]$. Fractures, head injuries, severe contusions, as well as the fear of another fall, are the causes of activity limitation, deterioration of performance, and in consequence, progressive loss of independence as well as the increasing need for help in everyday life [25]. The consequences result in the high cost of treatment provided in the form of surgery, prolonged hospitalization and longterm care for patients unable to live independently. The increasing number the elderly intensifies the importance of this issue.

\section{CONCLUSIONS}

The results of the presented study clearly show that December is the month in which occurs the most cases of elderly patients suffering from falls and the reason for their visits to hospital. A possible reason could be related to the weather. Furthermore, elderly patients visited hospital mostly on Mondays and Saturdays; however, in most cases, the injuries did not require hospitalization, as lower limbs were the main outcomes of the falls. Therefore, there is a need for further research related to the issue of falls among the elderly which would allow efficient management of this 'geriatric giant', as well as the proper allocation of health services in the case of aging societies.

\section{REFERENCES}

1. Polish Main Statistical Office GUS. The population projection for the period 2008-2035. Warsaw: Main Statistical Office; 2008.

2. Polish Main Statistical Office GUS. The report with the results. National Census of Population and Housing 2011. Warsaw: Main Statistical Office; 2012.

3. Fuller GF. Falls in the elderly. Am Fam Physician. 2000; 61(7): 2159-68, 2173-4.

4. Biercewicz M, Kędziora-Kornatowska K, Marzec A. Selected health problems in a population of elderly people. Ann Univ Mariae Curie Sklodowska [Med]. 2005; 30(Suppl XVI): 133-135 (in Polish, English abstract).

5. Bosacka M, Jóźwiak A, Wieczorowska-Tobis K. Effect of previous falls on functional status of elderly subjects hospitalized at daily psychogeriatric unit. Geriatria. 2010; 4: 81-85 (in Polish, English abstract). Available at http://www.akademiamedycyny.pl/geriatria/ archiwum/201002_geriatria_Wplyw\%20przebytych\%20upadkow\%20 Bosacka.pdf. (accessed: 02.12.2014).

6. Ostrowska B, Giemza C, Demczuk-Włodarczyk E, et al. Assessment of balance and gait in older nursing home residents. Physiotherapy. 2010; 18(4): 40-48.

7. Runge M, Schacht E. Multifactorial pathogenesis of falls as a basis for multifactorial interventions. J Musculoskelet Neuronal Interact. 2005; 5(2): 127-134.

8. Pruszyński J, Kuczerowska A. Falls. Polish Gerontology. 2004; 12(4): 177-181 (in Polish, English abstract).

9. Imamura T. Hirono N, Hashimoto M, et al. Fall-related injuries in dementia with Lewy bodies (DLB) and Alzheimer's disease. Eur J Neurol. 2000; 7(1): 77-79 (in Polish, English abstract).

10. Sterling DA, O'Connor JA, Bonadies J. Geriatric falls: injury severity is high and disproportionate to mechanism. J Trauma. 2001; 50(1): 116-9.

11. Gryglewska B. Elderly patient. Educational Program of the Polish Society of Hypertension. Polish Gerontology. 2003; 20(4): 119-147 (in Polish, English abstract).

12. Rubenstain LZ. Falls in older people: epidemiology, risk factors and strategies for prevention. Age and Ageing. 2006; 35(Suppl 2): ii37-ii41.

13. Word Health Organization. Health statistics and information systems. Available at http://www.who.int/healthinfo/survey/ageingdefnolder/ en/. (accessed: 2.12.2014).

14. Chodorowski Z. Geriatrics - Advances in diagnosis and therapy. 1st ed. Gdynia: Grafica; 2007. 
15. Word Health Organization. World Population Ageing. Report 2013. Available at http://www.un.org/en/development/desa/population/ publications/pdf/ageing/WorldPopulationAgeing2013.pdf. (accessed: 2.12.2014)

16. Clinical practice guideline for the assessment and prevention of falls in older people. Guidelines commissioned by the National Institute for Clinical Exellence (NICE). Royal College of Nursing; 2004.

17. Word Health Organization. Violence and Injury Prevention and Disability (VIP). France; 2007. Available at http://www.who.int/ violence_injury_prevention/other_ injury/falls/en/. (accessed: 20.08.2014).

18. Czerwiński E, Kumorek A, Milert A, et al. Causes of falls among women in the population of Krakow. Orthopedics, Traumatology, Rehabilitation. 2008; 10(5): 429-440.

19. Grochans E, Kardela B, Starczewska M, et al. The analysis of falls in patients hospitalized at geriatric ward. Hygeia Public Health. 2012; 47(3): 360-364. Available at_http://www.h-ph.pl/pdf/hyg-2012/hyg2012-3-360.pdf. (accessed: 2.12.2014).
20.Żakowska-Wachelko B. Outline of geriatric medicine. 1st ed. Warsaw: Wydawnictwo Lekarskie PZWL, Warsaw; 2000.

21. Pin Tan M, Kenny RA. Cardiovascular Assessment of Falls in Older People. Clin Intervent Aging. 2006; 1(1): 57-66.

22. Miturski A, Zybińska S, Wardach K, et al. Analysis of the prevalence of fractures in people over 65 years of age. Emergency duty. 2011; 4(2): 55-62.

23. Szczerbińska K. The circumstances and risk factors of recurrent and single falls in nursing homes. Polish Gerantology. 2011; 19(34): 161-170. Available at http://czasopisma.viamedica.pl/gp/article/ viewFile/19128/15063. (accessed: 2.12.2014).

24. Tinetti ME, Kumar Ch. The patient who falls. "It's Always a Trade-off". JAMA. 2010; 303(3): 258-266.

25. Tinetti ME, Gordin C, Sogolow E, et al. Fall-risk evaluation and management: challenges in adopting geriatric care practices. Gerontologist. 2006; 46(6): 717-725. 